\title{
A GESTÃO DEMOCRÁTICA MUNICIPAL NO ESTATUTO DA CIDADE E A TEORIA DO DISCURSO HABERMASIANA*
}

\author{
Janaina Rigo Santin**
}

RESUMO: O Estatuto da Cidade (Lei n. ${ }^{\circ}$ 10.257/2001) instituiu processos de gestão democrática e participativa na cidade, possibilitando aos cidadãos participarem na formulação, execução e acompanhamento de planos, programas e projetos de desenvolvimento urbano. Da mesma forma, trata da gestão orçamentária participativa, com a realização de debates, audiências e consultas públicas como condição obrigatória para aprovação das propostas das peças orçamentárias municipais. Por sua vez, a teoria do discurso habermasiana contribui para desenvolver esse modo discursivo de exercício do poder político, capaz de conjugar instituições representativas com instituições participativas, resgatando assim o potencial emancipatório da razão comunicativa. Mediante o procedimento democrático discursivo de tomada de decisões jurídico-políticas realizado nas audiências públicas concretiza-se um modelo de co-gestão entre representantes políticos e cidadãos na esfera municipal.

\section{CONSIDERAÇÕES INICIAIS}

A Lei n. ${ }^{\circ} 10.257$, de 11 de julho de 2001, denominada Estatuto da Cidade, foi editada

* Este artigo está baseado na tese intitulada "A Gestão Administrativa Participativa e o Poder Local", defendida pela autora no Doutorado em Direito da UFPR em junho de 2004.

** Doutora em Direito das Relações Sociais pela Universidade Federal do Paraná. Mestre em Instituições Jurídico-Políticas pela Universidade Federal de Santa Catarina. Advogada e professora da Faculdade de Direito da Universidade de Passo Fundo. Integrante do grupo de pesquisa no Constituição e Política, na linha de pesquisa Executivo e Políticas Públicas. para regulamentar os artigos 182 e 183 da Constituição Federal de 1988, traçando os objetivos da política urbana no Município e ditando diretrizes e princípios gerais para o processo de construção e manutenção da cidade. Destina-se a desenvolver sustentavelmente as cidades, de maneira planejada, justa e consistente, visando uma excelente qualidade de vida para a atual e as futuras gerações. Reforça a atuação do poder público local, com poderosos instrumentos que, se utilizados com responsabilidade, permitirão ações conseqüentes para a solução ou minimização dos sérios dilemas constatados nas cidades brasileiras. 
Constata-se a atual degradação do cenário urbano brasileiro, em especial ao longo das últimas décadas. A intensa imigração de pessoas do meio rural para o espaço urbanizado procurando condições mais dignas de sobrevivência, os graves problemas econômicos que assolam o país e que se refletem com maior intensidade nas grandes cidades, como a carência de empregos, de moradias, de transportes públicos adequados, bem como a falta de saneamento básico para a população, causam um doloroso desequilíbrio social, prejudicando o crescimento ordenado e sustentável das cidades.

Sabe-se que a ocupação do espaço urbano no Brasil historicamente foi marcada por uma intensa desigualdade, discriminação e exclusão social. A ausência de um planejamento para as cidades intensificou a expansão desordenada das periferias, em especial nas áreas metropolitanas, consolidando, por sua vez, na cidade formal, um mercado imobiliário restritivo e especulativo. Isso retrata a modernização incompleta de um país em desenvolvimento, e por conseqüência a sua desagregação no contexto global. Não se planejou as cidades para as classes mais pobres, porém para as classes média e alta, as quais teriam condições financeiras de adquirir imóveis nos espaços formais supridos por investimentos em trabalho, serviços públicos e infra-estrutura adequada. Para aquela categoria de pessoas restou ocupar o espaço informal das periferias, muitas vezes situados em áreas de risco para a saúde e vida das pessoas, bem como para o meio-ambiente, como encostas de morros, sujeitas a desabamentos, áreas de mananciais e de preservação ambiental.
Segundo Isabel Cristina de Eiras Oliveira (2001, p. 20)

A destruição dos benefícios decorrentes do processo de urbanização é historicamente injusta e resultante de décadas descaso, de incompreensão, de preconceito, e de atuação privilegiada voltada apenas para alguns setores da cidade (2001, p. 20).

É preciso alterar este estado de coisas, com o repensar do quadro urbano atual sob a interpretação do direito fundamental à moradia e à cidadania. Nas palavras de Grazia de Grazia

O Direito a cidade e à cidadania, entendido como uma nova lógica que universalize o acesso aos equipamentos e serviços urbanos a condições de vida urbana digna e ao usufruto de um espaço culturalmente rico e diversificado e, sobretudo em uma dimensão política de participação ampla dos habitantes das cidades na condução de seus destinos (2002, p. 16).

A Constituição Federal de 1988 possui como objetivos fundamentais a construção de uma sociedade livre, justa e solidária, bem como a erradicação da pobreza e da marginalização, reduzindo as desigualdades sociais e regionais para, com isso, buscar uma vida digna para todos. Da mesma forma, inseriu pela Emenda Constitucional n. 26 no rol de direitos sociais previstos no artigo 6. o direito fundamental à moradia. Assim, para atingir tais objetivos que foi editada a Lei n. ${ }^{\circ} 10.257$, de 10 de julho de 2001, atendendo à exigência constitucional de regulamentar o capítulo da política urbana da Constituição Federal de 1988. A execução dessa política de desenvolvimento urbano estará a cargo do Poder Público Municipal em conjunto com os cidadãos daquele Município, atuando conforme diretrizes fixadas em lei, visando com esse processo de 
co-gestão ordenar o pleno desenvolvimento das funções sociais da cidade e garantir o bem estar dos cidadãos. Unem-se esforços no intuito de reordenar as cidades, fazendo uma justa redistribuição do seu espaço físico, criando uma nova concepção de propriedade voltada ao interesse coletivo da população e à função social.

Nesse sentido, dentre as diretrizes gerais para a política urbana traçadas pelo Estatuto da Cidade, o presente artigo pretende ressaltar o disposto em seu artigo $2^{\circ}$, inciso II: é diretriz fundamental da política urbana a garantia da gestão democrática municipal, a ser obtida mediante "a participação da população e de associações representativas dos vários segmentos da comunidade na formulação, execução e acompanhamento de planos, programas e projetos de desenvolvimento urbano".

Para tratar da gestão democrática o Estatuto da Cidade reservou todo o seu capítulo IV, afirmando no artigo 43 que a garantia da participação da população na gestão municipal se dará mediante debates, audiências, consultas públicas, iniciativa popular de projetos de lei e de planos, programas e projetos de desenvolvimento urbano, bem como pela constituição de órgãos colegiados de política urbana e conferências sobre assuntos de interesse urbano, estas a serem desenvolvidas nos três entes federativos. Importante destacar que o artigo não é exaustivo, deixando em aberto a possibilidade da utilização de qualquer outro meio de participação que se faça necessário.

Assim, a participação dos cidadãos no processo legislativo do Plano Diretor, bem como das peças orçamentárias é condição formal para a sua aprovação perante o Poder Legislativo Municipal. Trata-se, portanto, de uma nova maneira de vislumbrar o exercício do poder político: conjugando instituições representativas com instituições participativas.

No aspecto urbanístico propriamente dito, deve o Município elaborar o Plano Diretor, regulamentando em âmbito local as disposições, princípios, diretrizes e instrumentos previstos no Estatuto da Cidade. Previsto no art. 39 do Estatuto da Cidade, é considerado como o instrumento básico da política de desenvolvimento e expansão urbana. Conforme os ensinamentos de Hely Lopes Meirelles,

é o complexo de normas legais e diretrizes técnicas para o desenvolvimento global e constante do Município, sob o aspecto físico, social, econômico e administrativo, desejado pela comunidade local (2003, p. 403).

O Plano Diretor é a lei geral que estabelece as prioridades nas realizações do governo local, pois deve abordar todos os problemas identificados a partir de um detalhado estudo sobre o espaço físico territorial urbano. Dessa forma, contribui para que sejam sanadas as necessidades de maior urgência e relevância da população nele identificada, disciplinando e controlando as atividades urbanas em beneficio do bem-estar da coletividade.

Os entes municipais com população acima de vinte mil habitantes, ou aqueles situados em aglomerações urbanas ou integrantes de regiões metropolitanas, inseridos em áreas de influência de empreendimentos com significativo impacto ambiental, bem como os Municípios que tiverem interesse em aplicar os instrumentos previstos no Estatuto da Cidade têm a 
obrigatoriedade de aprovar Plano Diretor conforme as novas disposições previstas no Estatuto da Cidade, para o que se dá o prazo de cinco anos de sua edição, devendo ser submetido à revisão a cada dez anos. Mas sua elaboração não ficará ao arbítrio do Poder Público, terá que ser garantida a participação da população na sua formulação, mediante a realização de audiências públicas e debates com as associações representativas dos vários segmentos da comunidade em busca de uma cidade democrática e aberta ao povo. $\mathrm{O}$ não atendimento desse requisito, sem prejuízo das demais sanções cabíveis, poderá resultar em improbidade administrativa do gestor público e vício formal no procedimento legislativo da lei municipal.

E ainda, ressalta-se o disposto no artigo 44, o qual trata da gestão orçamentária participativa. Trata-se de um dispositivo que deve ser interpretado em conjunto aos artigos 163 a 169 da Constituição Federal, relativos às finanças públicas, bem como com a Lei Complementar n. ${ }^{\circ}$ 101/2000 (Lei de Responsabilidade Fiscal). A novidade trazida pelo artigo 44 do Estatuto da Cidade é a questão da exigência da "realização de debates, audiências e consultas públicas sobre as propostas do plano plurianual, da lei de diretrizes orçamentárias e do orçamento anual, como condição obrigatória para sua aprovação pela Câmara Municipal.” Dessa forma, o referido dispositivo obriga ao Poder Público Municipal tornar efetiva a gestão orçamentária participativa, sob pena de declaração de nulidade formal das peças orçamentárias que não sejam elaboradas num processo de co-gestão com os cidadãos.

Dessa forma, as disposições trazidas no Estatuto da Cidade inauguram uma nova forma de gestão da coisa pública em âmbito municipal, a qual deverá conjugar a representação tradicional com mecanismos de democracia direta e de participação popular na gestão da coisa pública.

\section{O ESTATUTO DA CIDADE E A GESTÃO DEMOCRÁTICA MUNICIPAL}

Tendo em vista os inúmeros problemas apresentados por gestões municipais burocratizadas, afastadas dos cidadãos e das reais necessidades da comunidade, conjugados ao alto índice de endividamento das administrações municipais, o Estatuto da Cidade mostra-se como importante instrumento para o combate de tais vicissitudes. ${ }^{1}$

O exercício das funções e a administração dos recursos públicos têm suscitado amplas discussões no que diz respeito ao divórcio entre as necessidades dos cidadãos e o conteúdo das decisões sobre o desenvolvimento econômico e social. Muitos são os investimentos em projetos que necessitam de grande dispêndio de dinheiro público, porém não representam os interesses da sociedade. Essa problemática é observada tanto em âmbito nacional, como, por exemplo, com o projeto nuclear, com os investimentos para desenvolvimento da Amazônia e tantos outros, quanto na instância local. Muitas são as obras inacabadas ou superfaturadas, as quais prejudicam a sociedade ao fazer o contribuinte arcar com as conseqüências da má gerência e má aplicação dos recursos públicos.

1 Para um maior aprofundamento sobre os dispositivos legais previstos no Estatuto da Cidade, em especial no que tange à concretização do princípio constitucional da participação em âmbito municipal, ver (SANTIN, 2003). 
O que se constatou na modernidade é que tanto no liberalismo quanto no estatismo, bem como no paradigma de legitimação legal-burocrático weberiano, a sociedade civil esteve alijada do exercício do poder e dos mecanismos políticos decisórios de seu destino. Perante uma matriz estatal concebida a partir do contrato social, justificou-se a retirada da sociedade civil da persecução do bem comum em prol dessa entidade abstrata que é o Estado, prejudicando as iniciativas solidárias surgidas da sociedade civil. A legitimidade do poder estatal adviria daí, da garantia da igualdade formal, pelo procedimento, e da garantia da igualdade material, pela efetivação dos direitos sociais conquistados no século XX. Porém, tanto no privatismo quanto no estatismo, o Estado não logrou atingir os fins para os quais foi proposto. As promessas da modernidade foram descumpridas, culminando neste século XXI em uma situação de crise generalizada do Estado e de suas instituições.

Os indivíduos condicionaram-se a atribuir a responsabilidade pela organização de seu cotidiano a essa "esfera superior" distante e inatingível, chamada Estado. Esse quadro de sujeição social existe sem razão de ser. Ora, está-se diante de um Estado democrático de Direito, em que a população pode viver com liberdade e igualdade. $O$ poder atinente ao Estado é endossado pela sociedade, detentora originária do poder, eis que deixa de lado uma parcela de sua liberdade em prol dessa organização social e abstrata.

Contudo, neste limiar do século XXI denota-se uma dificuldade para o Estado legitimar-se de maneira racional em sociedades complexas. Esta crise resulta dos seguintes fatores: a) a adoção da reforma gerencial do Estado aos moldes neoliberais no intuito de superar o paradigma burocrático, relativizando-se direitos sociais e coletivos e delegando-se à esfera privada a prestação de serviços públicos; b) o descumprimento das promessas constitucionais, em especial os direitos sociais, sob a justificativa das dificuldades fiscais enfrentadas pelo Estado social ou desenvolvimentista; c) a falência do ritual formal da democracia representativa, que acaba por não atender ao interesse público e ao bem-estar social, comprometendo a legitimação do poder; d) a malversação das verbas públicas, em desconformidade com o interesse e necessidades dos cidadãos; e) corrupção e práticas clientelistas e patrimonialistas por parte dos detentores do poder político; f) a emergência de novos centros de poder alheios à esfera estatal, com forte influência na definição das tutelas jurídico-políticas nacionais, maculando a representação e prejudicando a democracia; g) o clamor por uma maior participação da cidadania no exercício do poder; h) o crescimento da organização da sociedade civil tanto em âmbito local como nacional e internacional. Portanto, já não é mais possível desconsiderar a urgência por uma maior participação da sociedade civil nos mecanismos de poder político.

Essa relação entre Estado e sociedade civil deve ser estreitada, com o estabelecimento de novos paradigmas de legitimação política capazes de introduzir uma gestão compartilhada entre essas duas categorias, combinando democracia representativa e democracia participativa. Na democracia representativa o povo não produz democracia, mas a recepciona. É consumidor: escolhe, 
entre duas ou mais ofertas, aquela que mais lhe convém. Jamais será produtor.

Sem dúvida, é impossível à democracia prescindir da representação ante a magnitude e complexidade dos Estados contemporâneos, de todo diferentes das polis gregas. As eleições são fundamentais para a democracia, como um procedimento instrumental da expressão da confiança popular em seus representantes. Entretanto, não absorvem a plenitude democrática, a qual deve ser mantida viva durante toda a gestão pública do eleito, como o impulso que vivifica e anima sua atuação.

A Constituição Federal de 1988, em seu artigo $1 .^{\circ}$ parágrafo único, adotou como regime de governo a democracia semidireta, ou seja, o governo é colocado nas mãos de representantes escolhidos pelo povo periodicamente nas urnas eleitorais, mas ainda é garantida a participação do cidadão na gestão pública mediante instrumentos diretos, previstos na própria Carta. Dessa forma, no ordenamento jurídico brasileiro a democracia representativa e a democracia participativa podem conviver conjuntamente, estando o Estatuto da Cidade em conformidade com as disposições constitucionais ao adotar a gestão democrática municipal como diretriz geral para a política urbana. Ou seja, os representantes são necessários; porém, a opinião do povo deve fundar e legitimar suas decisões.

Ao dividir o poder decisório com os cidadãos está-se diante de um mecanismo otimizador da gestão da coisa pública, eis que induz os representantes a agirem com maior transparência no intuito de desenvolver as funções sociais da cidade como um todo, garantindo o bem-estar de seus habitantes. Criam-se as condições para a tomada de decisões mais afinadas ao interesse da cidadania, bem como se aprimora o controle social sobre o poder político.

Coadunando conceitos como de participação popular, legitimidade, eficiência e controle do poder, Liana Portilho Mattos bem coloca a importância do Estatuto da Cidade na formação da gestão municipal.

A garantia da participação popular, a par de conferir legitimidade à gestão das cidades, tem uma outra faceta, qual seja, a de funcionar como o mais eficaz aparato de fiscalização dos atos da administração e do legislativo municipal. Esse controle social é importantíssimo para assegurar a efetiva aplicação dos instrumentos de reforma urbana trazidos pelo Estatuto da Cidade, ainda mais quando outras modalidades de controle, previstos na Constituição, sobretudo a legislativa e a judiciária, têm-se mostrado de duvidosa operacionalidade e eficiência. As normas contidas no Capítulo IV do Estatuto prevêem, assim, diversas formas de participação que dão concreção a essa dupla função social da participação popular: a de aferir legitimidade às ações municipais e a de exercer o controle dessas mesmas ações (MATTOS, 2002, p. 301).

Ao tornar plena a eficácia dos dispositivos democráticos na gestão da coisa pública previstos no Estatuto da Cidade, regulamentando-os no Município, o gestor público instrumentalizará o princípio constitucional da participação, conjugando democracia representativa com democracia participativa. Há uma evolução da tradição autoritária da gestão pública, na qual relevantes decisões eram "tomadas no interior de gabinetes e simplesmente impostas à população" (OLIVEIRA, 2002, p. 109).

A gestão democrática municipal exige do administrador público tanto competência decisória quanto a correspondência de suas escolhas às necessidades e objetivos da 
população. Para atingir esses objetivos conta-se não só com a sensibilidade do governante em captar as aspirações sociais mas, em especial, em adotar mecanismos para garantir direito de vez e voz à comunidade. Afinal, no dizer de Régis Fernandes de Oliveira, a democracia do século XXI deve superar sua visão de governo da maioria, pois para isso bastaria o processo eleitoral. A democracia deverá observar as regras do jogo, respeitar as minorias, possibilitar a participação dos cidadãos na tomada das decisões públicas, numa interação entre administrador e administrados. Logo, um governo democrático deverá respeitar o "intersubjetivismo de ações e reações como forma de sentir o pulsar da coletividade" (2002, p. 109), num processo complexo de tomada de decisões, capaz de superar a apatia do mero assentimento ou negação para ir mais além: captar o efetivo sentimento que pulsa dentro da sociedade.

Nas palavras do autor, é preciso combater o messianismo e os métodos carismáticos de gestão pública, baseados no líder inconteste e dono absoluto do destino do Município. O que deverá prevalecer nas administrações municipais são os debates, as audiências públicas e as consultas mediante plebiscito e referendo. Afinal, "os debates são a essência da democracia. A ausência do debate leva à falta de raciocínio dialético, em que prevalece apenas uma opinião e, o mais das vezes, nem sempre a correta" (OLIVEIRA, 2002, p. 109). Portanto, o processo decisório municipal, em especial após a edição do Estatuto da Cidade, deverá recepcionar a complexidade e a intersubjetividade presente na cidadania.

Entende-se assim, que viabilizando a prática da democracia participativa, como escreve Ladislau Dowbor (1995), grande parte das opções concretas sobre as condições de vida e de organização do cotidiano passa a ser gerida pelos próprios cidadãos. Contudo, é necessário incentivar o indivíduo a conhecer as possibilidades de contribuir na construção de sociedades sustentáveis, tornando-o participativo dos fatos relacionados ao seu interesse e, inclusive, ao interesse da coletividade. Para tanto, a maneira mais viável seria mediante uma atuação maciça dos meios de comunicação, bem como uma nova forma de educar nas mais diversas instituições de ensino, a fim de que ambos se tornem agentes da disseminação de valores democráticos. Afinal, esses dois fatores parecem mostrar-se como os meios de interação social mais eficiente e rápido num mundo globalizado.

Enfim, o processo de gestão democrática é entendido como maneira de planejar, produzir, operar e governar cidades submetidas ao controle e participação social (GRAZIA, 2002, p. 16). Porém, ele só será possível mediante a articulação entre Poder Público e cidadãos, cumprindo com os mecanismos do Estatuto da cidade em busca de cidades mais sustentáveis, tendo como centro a qualidade de vida da pessoa humana.

Restringir a participação do povo nos processos decisórios que digam respeito ao seu Município é recusar sua cidadania e, além disso, uma afronta aos princípios constitucionais fundamentais. A criação de canais institucionais que possibilitem à cidadania a tomada de decisões com igualdade de oportunidade ocasionará a racionalização de recursos e a redescoberta da cidadania em cada um e em grupo, levando a um maior comprometimento 
da população com o coletivo. Só assim será inaugurada uma gestão democrática participativa, de todos e para todos, a partir da construção de uma cidade mais humana e mais digna de se viver.

\section{A TEORIA DO DISCURSO DE JÜRGEN HABERMAS E AS AUdî̂nCIAS PÚBLICAS NO ESTATUTO DA CIDADE}

A presente pesquisa parte das contribuições teóricas de Jürgen Habermas (1992 e 1997), em especial suas reflexões acerca da importância da sociedade civil como esfera pertencente ao mundo da vida capaz de introduzir a racionalidade comunicativa nas esferas sistêmicas do Estado e do mercado. Dessa forma, a teoria do discurso habermasiana aplica-se às diretrizes de gestão democrática dispostas no Estatuto da Cidade, podendo-se desenvolver a teoria do discurso a partir da realização de audiências públicas para a aprovação do Plano Diretor municipal e peças orçamentárias, procedimento obrigatório para a sua aprovação. Trata-se de uma nova orientação para a ação administrativa municipal, a qual legitimará o exercício do poder político pela co-gestão das decisões públicas, rompendo as fronteiras burocráticas que separam o Município do cidadão.

É uma proposta procedimental, indicativa de um método democrático e discursivo de concepção das tutelas jurídico-políticas, mais legítimo, em que cada cidadão, individual ou coletivamente, será considerado não apenas destinatário, mas co-autor das normas municipais que serão a ele aplicadas. Assim, a legitimidade das decisões advirá do debate nas audiências públicas, "procedimentos pelos quais todos os afetados por normas sociais gerais e decisões políticas coletivas possam participar de sua formulação e adoção" (VIEIRA, 2001b, p. 59).

Mediante a discussão aberta, plural, intersubjetiva, permeável e autônoma realizada nas audiências públicas, em que impera a racionalidade comunicativa, os cidadãos, individuais ou organizados em movimentos sociais e associações, exercem a prática comunicativa e formulam suas pretensões baseadas no consenso e no predomínio do melhor argumento.

No entendimento de Liszt Vieira, a sociedade civil atuante nas audiências públicas passará a influenciar os mecanismos sistêmicos político e econômico, em que predominam o dinheiro e o poder, contribuindo para a sua democratização pela mudança nas regras de procedimento decisório e nas maneiras de participação política. Configurase uma "terceira dimensão da vida pública, diferente do governo e do mercado" (2001a, p. 63). Um espaço público não-estatal democrático, ${ }^{2}$ atuante em conjunto ao espaço estatal, garantindo que "os influxos democratizantes gerados na sociedade civil se tornem fontes de democratização do poder" (VIEIRA, 2001b, p. 77-78).

Essa perspectiva nada mais é do que o desenvolvimento de uma democracia representativa aliada à democracia participativa, caracterizada pela atuação conjunta da

2 Nesse sentido, conforme Jean L. Cohen e Andrew Arato, os movimentos democráticos dependem das novas formas autônomas do discurso, da associação e da solidariedade, ou seja, dos elementos característicos da sociedade civil (COHEN; ARATO, 2001. p.8). 
sociedade civil às instituições estatais, reconhecendo-se aquela como a origem e o destino do poder. Por meio do desenvolvimento dessa nova cultura participativa e associativa apresenta-se uma maneira de superação da tradição de clientelismo, personalismo e autoritarismo presente na história política de vários países, construindo-se "uma estrutura institucional mais democrática, posto que ancorada na sociedade civil e não nas elites que tradicionalmente controlam a sociedade política" (VIEIRA, 2001b, p. 78).

A democracia, mais do que um regime de governo, é uma metodologia a ser desenvolvida culturalmente (HUSZAR, 1965, p. 14), lançando suas luzes sobre todas as instituições sociais e jurídico-políticas. Deve ser reinventada cotidianamente. Logo, a ser concretizada a gestão democrática presente no Estatuto da Cidade dá-se um salto qualitativo para inserir na democracia representativa elementos de democracia participativa.

Sem dúvida, é impossível à democracia prescindir da representação ante a magnitude e complexidade dos Estados contemporâneos, de todo diferentes das polis gregas. As eleições são fundamentais para a democracia, como um procedimento instrumental da expressão da confiança popular em seus representantes. Entretanto, não absorvem a plenitude democrática, a qual deve ser mantida viva durante toda a gestão pública do eleito, como o impulso que vivifica e anima sua atuação.

Assim, não se pode resumir a democracia apenas no poder do povo em eleger seus representantes de quatro em quatro anos. Essa concepção favorece o desinteresse sistemático dos administrados pela vida política, a apatia, a abstenção, a resignação ante a corrupção, a falta de confiança nos governantes e a abdicação da participação na vida pública, fatores que corroem o ideal democrático. Essa visualização formal da democracia esvazia seu escopo de prática de resistência ao poder do Estado. Um discurso destinado a oferecer a segurança que afasta toda a possibilidade de interrogação, interpretação e questionamento sobre as instituições estatais e a maneira como se dão as gestões públicas. Tal maneira de encarar a democracia não é nada mais que um totalitarismo mascarado, um modelo com poucas oportunidades de práticas de resistência e de criatividade, destinado à uniformização do pensamento e à desmobilização dos cidadãos.

A falta de confiança do povo na classe política é a expressão desse sentimento de alienação do poder de participar da gestão da coisa pública, que não é mais vista como questão da cidadania, mas dos próprios titulares da gestão, os quais se apropriam dela e de seus fins, numa ruptura com a legitimidade do exercício político. O povo precisa sentir-se como o verdadeiro titular do poder e acreditar que seus interesses deverão ser os únicos objetivos dos governantes, como professa o ideal democrático.

Em qualquer sociedade em que se reduz o campo político ao campo estatal, em que as maiorias são manipuladas por uma cultura de indiferença e apatia política, a democracia será apenas formal. A democracia não se constrói com palavras nem com dogmas, mas com métodos democráticos a serem fomentados no interior das instituições, para então alcançar a democratização do processo político. Uma sociedade democrática é aquela que realiza práticas democráticas e adota métodos democráticos, respeitando a 
pluralidade e a heterogeneidade de seu povo; que aceita a interpretação crítica de suas instituições e o conflito, negando as verdades absolutas, prontas, plenas e completas. Afinal, o conflito é o elemento constitutivo da vida, da política e do saber, com vistas a evoluir e alcançar o novo.

\section{CONCLUSÃO}

Ao aproximar o poder decisório daqueles diretamente atingidos pelas políticas públicas dá-se um grande passo no sentido de que as escolhas jurídico-políticas sejam mais acertadas, otimizando a aplicação do dinheiro público e legislando de acordo com os interesses e necessidades da população. Com a adoção de normas legais e políticas públicas formuladas nos espaços comunicacionais gerados nas audiências públicas, aumentar-se-á a legitimidade das decisões políticas, jurídicas e legislativas, facilitando o posterior cumprimento dessas decisões. Afinal, as pessoas que participaram como atores do processo, por certo, estarão mais vinculadas às decisões tomadas. ${ }^{3}$

Com a participação da sociedade civil nas audiências públicas realizadas a partir das disposições do Estatuto da Cidade as

3 Ao falar da questão da desobediência civil e da falta de efetividade das decisões públicas, Jürgen Habermas assevera que "tais atos de transgressão simbólica não-violenta das regras se auto-interpretam como expressão do protesto contra decisões impositivas as quais são ilegítimas no entender dos atores, apesar de terem surgido legalmente à luz de princípios constitucionais vigentes. (...) a desobediência civil sempre reclama implicitamente que a formação legal da vontade política não pode se desligar dos processos de comunicação da esfera pública" (HABERMAS, 1997. v.2, p.117). pessoas passarão a entender as limitações de recursos do ente público para dar conta da satisfação de todas as necessidades, a aceitar compromissos e a separar reflexivamente sua própria perspectiva individualizada para reconhecer a prioridade de outras. Aprendem a valorizar e reconhecer a diferença, perceber que as dimensões de seus requerimentos precisam ser ponderadas diante das demais necessidades constatadas, definindo quais serão priorizadas e quais abandonadas ou modificadas. (COHEN; ARATO, 2001, p. 42)

Por fim, conclui-se que os dispositivos presentes no Estatuto da Cidade relativos à gestão democrática municipal só atingirão sua finalidade se embasados em uma sociedade civil moderna, com o desenvolvimento de uma teoria democrática participativa pautada nos mecanismos comunicativos e na teoria do discurso habermasiana (COHEN; ARATO, 2001, p. 15). Com essa perspectiva, quer-se conceber uma sociedade civil e uma esfera pública capaz de se constituir e governar a si própria, destinatária e também autora das decisões públicas. Para tanto, é mister fortalecer, mediante a participação popular, as instituições políticas representativas clássicas, as quais passarão a atuar em comunhão a novas instituições - mais democráticas e participativas. Fomentar valores coletivos e de uma ética da solidariedade, na qual impera a racionalidade comunicativa proveniente do mundo da vida. Logo, é um processo de redemocratização da democracia, obtido mediante um processo comunicativo que alia democracia representativa à democracia participativa e é produzido na esfera pública - cujas decisões surtirão efeitos na esfera estatal. 


\section{REFERÊNCIAS}

COHEN, J. L.; ARATO, A. Sociedad Civil y

Teoría Política. Tradução de: Roberto Reyes Mazzoni. México: Fondo de Cultura Económica, 2001.

GRAZIA, G. Estatuto Da Cidade: Uma Longa História Com Vitórias E Derrotas. In: OSÓRIO, L. M. (Org.). Estatuto da Cidade e Reforma Urbana: Novas Perspectivas para as Cidades Brasileiras. Porto Alegre: Sergio A. Fabris, 2002.

HABERMAS, J. Direito e Democracia: entre facticidade e validade. Tradução de: Flávio Beno Siebeneichler. Rio de Janeiro: Tempo Brasileiro, 1997. v. 1 e 2.

HABERMAS, J. Teoría de la Acción Comunicativa. Madrid: Taurus, 1992. v. 1 e 2.

HUSZAR, G. B. Aplicações Práticas da Democracia. Tradução de: J. L. Melo. Rio de Janeiro: Record, 1965.
MATTOS, L. P. Da Gestão Democrática da Cidade. In: MATTOS, L. P. (Org.). Estatuto da Cidade Comentado. Belo Horizonte:

Mandamentos, 2002.

OLIVEIRA, I. C. E. Estatuto da Cidade: para compreender... Rio de Janeiro: IBAM/DUMA, 2001.

OLIVEIRA, R. F. Comentários ao Estatuto da Cidade. São Paulo: Revista dos Tribunais, 2002.

SANTIN, J. R. O Estatuto da Cidade e a Gestão Democrática Municipal. Revista Interesse Público, Porto Alegre, ano 5, n. 21, p. 220-229, set./out. 2003

VIEIRA, L. Cidadania e Globalização. 5.ed. Rio de Janeiro: Record, 2001a.

VIEIRA, L. Os Argonautas da Cidadania: a sociedade civil na globalização. Rio de Janeiro: Record, 2001b. 